\title{
AUTONOMIA PRIVADA NAS OPERAÇÕES DE AQUISIÇÃO E VENDA DE MOEDAS VIRTUAIS
}

\author{
Lidiana Costa de Sousa Trovão \\ Mestranda em Direito pela Universidade de Marília \\ (UNIMAR). Especialista em Direito Processual Civil e \\ Direito Civil pela UNIDERP/Anhanguera/MS. Graduada \\ em Direito pela UFMA e em História pela UEMA. \\ Professora e advogada. \\ lidianacst@hotmail.com

\section{Rogerio Mollica} \\ Doutor em Direito pela Universidade de São Paulo. \\ Professor do Programa de Pós-Graduação em Direito da \\ Universidade de Marília (UNIMAR). \\ rogerio.mollica@mrlaw.com.br
}

\begin{abstract}
RESUMO: A presente pesquisa tem por escopo analisar a autonomia privada manifestada na operação de aquisição e venda de moedas virtuais, considerando as características clássicas do negócio jurídico na modalidade contrato e as nuances sofridas para adequar-se a esse novo modelo de transação comercial. Não obstante, e mantendo a maioria das demais características que a compõe, existente no ordenamento jurídico o envolvimento de diversas atividades comerciais em torno das chamadas criptomoedas, as quais não escapam ao albergue do direito brasileiro. A importância da discussão acerca do tema reside na necessidade de delimitar direitos e obrigações dentro da esfera negocial que compõem a aquisição e venda de moedas virtuais, ainda não regulamentadas no Brasil. A autonomia privada, como manifestação inconteste da vontade das partes, funciona como vetora nas operações que circundam os contratos que envolvem as criptomoedas, eis que nesse tipo de transação, referido princípio não é afastado. E como máxima expressão dessa autonomia negocial, a criação de moedas virtuais desafiam as normas vigentes e se apresentam, até então, como instrumentos legais, ou seja, que não violam as normas. Assim, pretende-se verificar em que medida a autonomia privada tenha que estar presente nessas relações comerciais, se existe a possibilidade de haver atividades de negociação de moedas virtuais em que não se observe claramente a autonomia privada, ou casos em que ela seja relativizada. Utilizou-se pesquisa qualitativa, doutrina nacional e artigos científicos sobre o tema em questão.
\end{abstract}

PALAVRAS-CHAVE: Autonomia privada. Moedas virtuais. Criptomoedas.

\section{Private autonomy in the operations of buying and selling virtual currencies}

ABSTRACT: The scope of this research is to analyze the private autonomy manifested in the operation of the purchase and sale of virtual currencies, considering the classic characteristics of the legal business in the contract modality and the nuances suffered to adapt to this new Business transaction model. Nevertheless, and keeping most of the other characteristics that composes it, existing in the legal order the involvement of various commercial activities around the calls Criptomoedas, which do not escape the hostel of Brazilian law. The importance of the discussion on the topic lies in the need to delimit rights and obligations within the negotiating sphere that make up the purchase and sale of virtual currencies, which are not 
yet regulated in Brazil. Private autonomy, as a manifestation incited by the will of the parties, acts as a vector in the operations surrounding the contracts involving the criptomoedas, and this type of transaction, said principle is not removed. And as a maximum expression of this negotiating autonomy, the creation of these virtual currencies defies the prevailing norms and has hitherto been as legal instruments, that is, that do not violate the norms. Thus, it is intended to verify the extent to which private autonomy has to be present in these commercial relations, whether there is the possibility of contracts for the purchase and sale of virtual currencies in which there is clearly no obvious private autonomy, or cases where She's relativized. It was used for both the deductive method, based on doctrinal sources, legislation and scientific articles.

KEYWORDS: Private autonomy. Virtual currencies. Crypto-coins.

\section{INTRODUÇÃO}

O estudo realizado foi desenvolvido com o intuito de verificar a atuação da autonomia privada enquanto princípio norteador na formação dos contratos, cujo enfoque se volta para as operações de negociação de moedas virtuais, as chamadas criptomoedas, tipo de transação comercial virtual em que se faz a mineração (busca) desses bens móveis em ambiente totalmente virtual e para as quais se atribui valor monetário de compra em determinadas situações.

A análise da autonomia privada dentro desse ambiente ainda em exploração é tendente a reafirmar a necessidade de atribuir às relações virtuais a adequação às normas vigentes, excepcionando-se a criação de normas próprias, a não ser que se trate de situação nunca antes vista, o que não é o caso. Nessa esteira de ideias, no ordenamento jurídico brasileiro não se pode admitir que existam situações que estejam à margem da nossa legislação, e no contexto da aquisição de moedas virtuais, embora seja uma operação de certa forma internacionalizada, para negociações feitas aqui no Brasil (por serem o direito subjetivo e a liberdade contratual os instrumentos da autonomia privada), as normas que o regem devem seguir os preceitos de direito aqui aplicados.

Dessa forma, e não obstante à incidência dos demais princípios que norteiam a feitura dos contratos, a autonomia privada toma destaque tendo em vista que se manifesta em dois momentos subjetivos determinantes. $\mathrm{O}$ primeiro diz respeito à iniciativa de escolher as moedas virtuais como instrumento de troca para realização do negócio jurídico, aqui destacando-se a ausência de liquidez dessas moedas e a alto risco dessas operações. Depois, e de forma decisiva, a utilidade que será dada a esse bem (moeda), seja como forma de investimento ou para compra de bens (ações) ou serviços (como em contratos futuros).

A operação que circunda as atividades de aquisição e venda envolvendo moedas virtuais está inserida no contexto dos contratos, fixados como os de compra e venda ou permuta, uma vez que, mesmo sendo bem de valor flutuante, é através de moeda corrente que ele é adquirido em valor unitário, daí iniciada a operação de aquisição, que deve ser feita através dos chamados mineradores, detalhes que serão melhor tratados no texto. Em seguida, uma segunda operação de compra, que se dará na aplicação dessas moedas, a exemplo das operações acima mencionadas. Portanto, o indivíduo ou empresa ao adquirir moedas virtuais, tem que estar ciente de que sua autonomia deverá estar muito bem dimensionada e aplicada, para que, em determinados momentos, por envolver operações de risco, não sejam lesados e fiquem impossibilitados de reclamar o prejuízo, risco exponenciado pelo fato da atividade não ser totalmente regulamentada. 
O presente trabalho almeja, assim, uma análise da vinculação exercida pela autonomia privada sob uma perspectiva civil-constitucional-consumerista, vinculada a boa-fé objetiva, função social dos contratos e equilíbrio econômico, no que pertine à aquisição e venda de moedas virtuais, dado ao seu exponencial crescimento mundial nos últimos anos. Essa análise é tendente a concluir que as operações comerciais envolvendo as criptomoedas devem se pautar pelas normas contratuais vigentes, porém, em determinados momentos e de acordo com algumas nuances, a insegurança da transação faz com que diversos desses princípios sejam mitigados, e por vezes, afastados.

Para a condução deste trabalho, então, foi utilizada pesquisa qualitativa, doutrina nacional e artigos científicos sobre o tema em questão. Dividiu-se a pesquisa em momentos. Partiuse da análise do princípio da autonomia privada no Direito Civil Contratual à luz da teoria geral dos contratos. Após, passou-se a análise dos contratos que envolvem negociações de aquisição e venda de moedas virtuais e suas relações com os Direitos Constitucional, Civil e do Consumidor. Fez-se, paulatinamente, uma análise sobre a incidência da autonomia privada como vetora das negociações de aquisição e venda de criptomoedas, assim como a operação econômica que a circunda. Por fim, foi analisado cada um dos preceitos contratuais da boa-fé objetiva, função social dos contratos e equilíbrio econômico face a essa nova tecnologia. Espera-se que ao final sejam atingidos os objetivos propostos.

\section{A AUTONOMia PRIVAdA COMO FORMA DE DETERMINAR O REGULAMENTO CONTRATUAL}

A significação da palavra contrato encontra diversos entendimentos, dentre eles aquelas que dizem respeito ao processo ou às fases de formação do instrumento e ao seu resultado ou produto, perfazendo o todo de cada elemento que é afeto a direitos e obrigações às quais as partes se submetem.

Diante dos interesses colocados pelas partes, a fixação e tradução das obrigações jurídicas deverão estar em consonância com a conveniência jurídica do próprio contrato, levando-se em conta o fato que o instrumento contratual é apenas uma forma de externar o exercício de iniciativas econômicas. Para que esse instrumento seja idealizado e depois colocado em prática, é necessário que as partes estejam cientes de todos seus anseios diante da celebração contratual. Acerca do regulamento contratual, Roppo (1998, p. 126-127) preleciona que:

\footnotetext{
Determinar o regulamento contratual (ou conteúdo) significa, substancialmente, definir que composição, que arranjo recíproco receberão os interesses das partes, coenvolvidos na operação econômica e a que o contrato é chamado de dar veste e vinculatividade jurídica. [...] significa, em suma, fixar e traduzir em termos jurídicos, os termos da operação econômica prosseguida com o contrato, definir as variáveis que no seu conjunto refletem a conveniência econômica do próprio contrato.
}

Essa atividade não foge às mais diversas formas que se externa a operação comercial de troca, que deu origem à compra e venda. A instituição de moeda corrente, o que se convencionou chamar de dinheiro, sofreu um processo que culminou com a determinação do modo que essas operações econômicas seriam efetuadas. A relação existente entre as chamadas moedas virtuais ainda é alvo de diversas críticas. Diga-se com total razão, eis que não se tem uma determinação unânime sobre qual seja a natureza jurídica das criptomoedas.

$\mathrm{O}$ ato de firmar um instrumento contratual, face a todas as capacidades e vontades das partes e diante do objeto avençado, constitui um verdadeiro ato de arbítrio do homem, o que para Rodrigues Junior (2004, p. 118) é "o exercício da faculdade que ele tem de dispor dos 
diversos meios que possui de desenvolver o seu ser e preencher os fins de sua natureza, de sua existência intelectual, moral e física".

Importante destacar que a autonomia privada, nas palavras de Boulos (2003, p. 125) “enquanto autonomia, não é originária.", pois sua manifestação pode ocorrer de forma variável "de acordo com a forma pela qual é regulamentada por cada ordenamento jurídico, em razão das modificações decorrentes, por exemplo, da atividade legislativa.”. Vale dizer, ainda, que com o advento do Código Civil de 2002 houve uma forma inovadora na disciplina da figura do abuso de direito e "ao estabelecer que o limite da liberdade contratual é a função social do contrato, traçou os contornos da autonomia privada de formas diversas daquela desenhada pelo legislador de 1916", utilizando-se de "normas de ordem pública ou de imperatividade absoluta, que constituem o principal meio de que se vale o Estado para limitar a autonomia privada." (BOULOS, 2003, p. 126).

A função social do contrato, informada pelos princípios constitucionais da dignidade humana (art. $1^{\circ}$, III), do valor social da livre iniciativa (art. $1^{\circ}$, IV), estes, fundamentos da República, e ainda os princípios da igualdade substancial (art. $3^{\circ}$, III) e da solidariedade social (art. $\left.3^{\circ}, \mathrm{I}\right)$, que compõem os objetivos da República, compele às partes o dever de perseguir, juntamente aos interesses individuais, os interesses extracontratuais socialmente relevantes, os quais também merecem tutela, relacionados ao contrato ou por ele de alguma forma atingidos. (TEPEDINO, 2008, p. 393)

Desse modo, a liberdade condicionada de contratar deve obedecer aos ditames legais, sob pena de se tornar uma iniciativa abusiva. No atual Código Civil, "além de alargar as hipóteses por meios das quais a regra (repita-se, ainda vigente) 'os pactos tem que ser cumpridos' pode e deve ser afastada, estabeleceu um regime de cláusulas gerais que contém princípios”, e estes, "constituem verdadeira limitação à liberdade contratual e, em maior escala, à própria autonomia privada." (BOULOS, 2003, p. 129). O art. 187 do Código Civil de 2002 é um exemplo de cláusula geral, que repudia o abuso de direito, como também o é a boa-fé objetiva do art. 422 e aquela que veda o enriquecimento sem causa (arts. 884 e ss). Na legislação consumerista, "dentre dessas práticas abusivas, encontram-se temas relacionados à oferta, publicidade, cobrança de dívidas, banco de dados e cadastro de consumidores, por exemplo" (FERNANDES; SOUZA, 2017, p. 56).

Sob esse aspecto, o novo diploma civil tratou "de reconhecer como cláusula geral, que a liberdade contratual possui a razão de ser e seu limite na função social do contrato", de modo a deixar claro que "o princípio da função social do contrato é a pedra angular do novo Direito contratual brasileiro" (BOULOS, 2003, p. 129) e deve nortear todas as contratações, sejam exteriorizadas em contratos típicos ou atípicos. De mais a mais, a possibilidade de haver uma liberdade é passo para que haja um abuso, devendo os particulares perseguirem seus anseios por meio de manifestação de vontade, a partir das limitações funcionais que o contrato tem perante a sociedade.

Do mesmo modo se põe a boa-fé objetiva como princípio que reflete valores éticos de lealdade, correção e veracidade, "o que explica a sua irradiação difusa, o seu sentido e alcance alargados, conformando todo o fenômeno contratual e, assim, repercutindo sobre os demais princípios, na medida em que a todos eles assoma o repúdio ao abuso da liberdade contratual" (NEGREIROS, 2002, p. 116).

Numa perspectiva constitucional, “o princípio da boa-fé assenta cláusula geral de tutela da pessoa humana - em que se presume parte integrante de uma comunidade, e não ser isolado, cuja vontade em si mesma fosse absolutamente soberana". Por essa razão, "é possível conduzir o princípio da boa-fé ao ditame constitucional que determina como objetivo fundamental da 
República a construção de uma sociedade solidária, a qual o respeito pelo próximo seja um elemento essencial de toda e qualquer relação jurídica.” (NEGREIROS, 2002, p. 117).

Além desse enfoque constitucional, evidencia-se, portanto, a necessidade de fiscalizar o comportamento do sujeito contratante, uma vez que "se o Código de Defesa do Consumidor [...] nessa nova fase da teoria contratual serviu de mote teórico para o relançamento da boa-fé no plano contratual, [...], eis que a legislação de consumo, bem como toda ordem contratual, estão fundidas no princípio constitucional da livre iniciativa" (NALIN, 2003, p. 126), e desse modo não é exclusiva do CDC.

Conforme entende Tartuce (2005, p. 197):

\begin{abstract}
Ao lado da função social dos contratos, a boa-fé objetiva procura valorizar a conduta de lealdade dos contratantes em todas as fases. Na dúvida, os contratos devem ser interpretados conforme a boa-fé (art. 113 do novo Código Civil - função de interpretação da boa-fé). Em reforço, lembramos a interpretação a favor do consumidor (art. 47 do CDC) e do aderente (art. 423 do novo Código Civil).
\end{abstract}

As relações contratuais, portanto, se difundem no ordenamento e se estreitam conforme se aproximam das situações concretas, em que se deve sempre observar os princípios norteadores das atividades negociais. Assim, ao observar as atividades que circundam as negociações envolvendo moedas virtuais pode-se relacioná-las com situações privadas, patrimoniais e consumeristas, no instante em que se verifica a predominância de capital privado, de cunho patrimonial e dentro de uma relação de consumo entre as empresas startups (empresas de tecnologia) ou até casas de câmbio especializadas em comercializar esse tipo de moeda, e investidores e entusiastas das moedas virtuais, como forma de patrocinar investimentos em novos projetos ligados às criptomoedas.

Essas novas técnicas de contratação, na visão de Glitz (2002, p. 210), "se tornaram necessárias, juntamente com novos tipos contratuais que proporcionassem respostas rápidas aos desafios recém surgidos", e assim, "se apresentassem de modo mais condizente com a realidade célere do capitalismo do Século XXI.”. A contratação eletrônica aqui tratada, como modo de exteriorização dessa autonomia, compõe o quadro de complexidade das recentes tecnologias, fazendo parte dos novos fenômenos sociais e econômicos que não encontram interpretação e aplicação no Direito Civil quando buscadas respostas para seus problemas, fazendo-se necessário uma nova forma de interpretação dos conceitos tradicionais.

Veja-se que esses reflexos da evolução tecnológica são facilmente observados nas relações contratuais. Nos dias de hoje, essas relações estão mais intimamente ligadas a novas formas de contratação do que àqueles celebrados solenemente no passado. $\mathrm{O}$ ordenamento jurídico deverá estar atento a essas modificações em progressão aritmética, a fim de evitar que fiquem a margem do direito e se tornem meios concretos para práticas ilícitas no meio virtual, dentre as quais está a aquisição e venda de moedas virtuais.

\title{
2 A AUTONOMIA PRIVADA COMO VETORA DAS OPERAÇÕES QUE CIRCUNDA A AQUISIÇÃO E VENDA DE MOEDAS VIRTUAIS
}

As tradicionais operações de compra e venda de mercadorias envolvem a realização de trocas, em geral, por meio de moeda corrente, de forma bilateral. $\mathrm{O}$ vendedor se obriga a transferir à outra parte o domínio da coisa, "mediante a contraprestação de certo preço em dinheiro" (GONÇALVES, 2013, p. 214). Referida avença pode ter como objeto bens de toda natureza, móveis ou imóveis, cujo caráter obrigacional é recíproco, porém, a transferência do domínio da coisa cabe ao vendedor em benefício do comprador por meio da tradição. 
Na operação de aquisição e venda de moedas virtuais, a criptomoeda é o bem transacionado, espécie de unidade monetária virtual, representativa nesse tipo de negócio. As partes se identificam como sendo comprador, qualquer pessoa, e como vendedor, em regra, as startups ou casas de câmbio especializadas no assunto. A negociação se dá por meio congênere ao tradicional IPO - Initial Public Offer, ou oferta pública inicial (quando uma empresa abre seu capital na bolsa de valores), com traços peculiares ao financiamento coletivo também conhecido como crowdfunding.

Toda essa transação, inclusive no momento que a antecede, é marcada pela autonomia privada, cujo vetor se manifesta através da liberdade de contratar. Conforme entendimento de Sztajn (2011, p. 3) "na área financeira a liberdade de contratar é fundamental para a inovação, e estimula a criatividade dos agentes que engendram soluções para atender as novas exigências do tráfico negocial"'.

É inegável que as criptomoedas, enquanto bens negociáveis virtualmente, a exemplo dos bitcoin e ethereum, são frutos da autonomia privada, exercício da liberdade conferida às partes para negociarem, criando instrumentos que possam ser utilizados funcionalmente como bem intermediário de troca e "seu poder liberatório decorre de pacto entre contratantes [...]", e "não há como garantir limites de criação dessa mercadoria, [...]. E, nada obstante, a criação dessa moeda virtual, [...] não viola norma jurídica cogente." (BAROSSI FILHO; SZTAJN, 2015, p. 1693).

A dinâmica que envolve as operações virtuais de aquisição e venda de moedas digitais apresenta limites. Embora a atividade de mineração (no blockchain ${ }^{1}$ ) de bitcoins ainda não esteja regulamentada no Brasil, já existe uma grande movimentação de operações envolvendo esse tipo de negócio, o que tem sido um problema enfrentado pelas autoridades no assunto. $\mathrm{O}$ órgão competente para possível regulamentação é relegada à Comissão de Valores Mobiliários que reconhece, a depender do contexto econômico, que a emissão de ativos virtuais pode representar valores mobiliários nos termos do Art. $2^{\circ}$ da Lei 6.385/76.

Assente na doutrina é o entendimento de que as moedas virtuais ou criptomoedas na verdade não são moedas, mas apenas meios de troca, e assim "a bitcoin não é dotada de uma das funções usuais de qualquer moeda fiduciária, a aptidão para ser unidade de conta". Por isso, "pode ser vista como meio de troca que facilita "permutas". E arrematam os autores: "bitcoin não é moeda, mas meio de troca, cuja função primordial é evitar custos" (BAROSSI FILHO; SZTAJN, 2015, p. 1689).

À luz dos princípios que regem o direito contratual, sob análise da compra e venda de moedas virtuais, essa operação encontra alicerce na ampla liberdade contratual, na qual as partes por suas liberalidades escolhem pactuar por meio desse bem, sem qualquer interferência do Estado. O negócio jurídico avençado poderia ser classificado como contrato atípico, porque não regulamentado no ordenamento jurídico, embora gerado por necessidades e interesses das partes (autonomia privada). Porém, há quem sustente que os contratos envolvendo criptomoedas classifiquem-se como sendo "contrato de troca ou permuta, ou seja, um escambo de bens que forma obrigações de dar coisa certa.” (MARTINS, 2016, p. 24).

Não obstante, o negócio jurídico pactuado perpassa momentos de subjetividade determinantes. A escolha das moedas virtuais como instrumento de troca para negociação, ainda que

1 Blockchain é uma espécie de banco de dados, que “consiste em dois aspectos: um ‘livroregistro' que mostra publicamente o histórico de todas as transações feitas pelas chaves públicas, e um processo de validação por meio de aglutinação das transações em blocos encadeados, cuja decodificação se dá em função dos blocos adjacentes. Os mineradores, para terem a chance de receber as taxas e os novos lotes de moedas, recebem esses blocos para serem decodificados, com o intuito de validar em massa as transações efetuadas." (MARTINS, 2016, p. 142). 
ciente dos riscos a elas inerentes, a compreensão da utilidade que será agregada (forma de investimento em ações) ou para compra de bens (mercadorias) ou serviços (como em contratos futuros), todos frutos da liberalidade que permeia a autonomia privada, a mesma que permite que essa negociação com moedas virtuais não caia nas raias da ilegalidade, pela garantia que se tem de pactuar licitamente sobre o que desejarem e da forma como bem entenderem as partes. Nesse contexto, se está diante do exercício do "direito subjetivo (como meio colocado à disposição dos particulares para realizarem seus interesses) e a liberdade negocial ou contratual (como faculdade de celebrar negócios jurídicos) que são os meios [...] de adquirir e exercer os direitos subjetivos", e assim, "apresentam-se como mecanismos jurídicos colocados pela ordem jurídica a disposição dos particulares para que esses operem essa auto-regulamentação de acordo com seus interesses.” (BOULOS, 2003, p. 125).

A mesma ordem jurídica impõe limites da faculdade de regulamentação. No caso das negociações envolvendo criptomoedas, aplicam-se todas as regras que norteiam os contratos de um modo geral, pois a pactuação, embora pautada na autonomia da vontade, não pode ter caráter absoluto, supralegal. O limite inicial se dá pela supremacia da ordem pública, que como cláusula geral "está no nosso ordenamento por meio do art. 17 da Lei de Introdução às Normas do Direito Brasileiro, regra de direito internacional privado que retira eficácia de qualquer declaração de vontade ofensiva à ordem pública." (GONÇALVES, 2013, p. 44). São consideradas de ordem pública "as regras que o legislador erige em cânones basilares da estrutura social, política e econômica da Nação. Não admitindo derrogação, compõem leis que proíbem ou ordenam cerceando nos seus limites a liberdade de todos.” (PEREIRA, 2016, p. 25-26).

Assim, não se admite que sejam infringidas as regras de bons costumes, conceito que decorre da observância de normas de convivência, de acordo com a conduta social pelos sentimentos morais da época, ou seja, a forma como a sociedade tolera determinados comportamentos. Pode-se definir que bons costumes sejam "aqueles que se cultivam como condições de moralidade social, matéria sujeita a variações de época a época, de país a país, e até dentro de um mesmo país e mesma época." (GONÇALVES, 2013, p. 45.). A noção de ordem pública e de respeito aos bons costumes são verdadeiros freios e limites à liberdade contratual.

A boa-fé objetiva nessa atividade já não traz tanta certeza como as que foram ditas acima. Isso porque as atividades que circundam as negociações de criptomoedas não são ainda regulamentadas, e essas "moedas" são consideradas altamente voláteis e não confiáveis. O risco de investimento nessas operações, envolvendo fraudes, perdas de valores investidos em face da flutuação da cotação, dentre outros, constituem algumas das situações que podem ocorrer. No Código Civil, a boa-fé é definida não somente como critério de interpretação da declaração de vontade (art. 113) e de violação da abusividade no exercício de direitos subjetivos (art. 187), mas igualmente como uma regra de conduta imposta aos contratantes (NEGREIROS, 2002, p. 126).

Recentemente, nos Estados Unidos, o FBI, polícia federal americana, fechou uma pequena corretora de criptomoedas (Coingather), acusada de cometer crimes relacionados a operações sem licença, no início das operações com moedas virtuais (GUSSON, 2018). Essa empresa, fundada em 2014, não acumula muitas queixas de seus usuários, a não ser, em relação a taxas praticadas até 10 vezes maiores que a média do mercado nesse ano. Já no ano de 2017, começaram a surgir suspeitas de que seus funcionários estivessem envolvidos em atividades ilícitas, o que acabou sendo confirmado e culminando com a referida operação.

No Brasil, o investimento em moedas digitais tem chamado a atenção de veículos de comunicação como o jornal norte-americano Financial Times, que descreveu os líderes do movimento de bitcoins no Brasil como "anarquistas do capitalismo", ao buscar entender o 
assombroso crescimento do mercado de criptomoedas no país (NASSIF, 2018). É claro que a ascenção da moeda virtual no Brasil acompanha os demais países, haja vista ser de incidência mundial. O que chama a atenção, no entanto, é que esse tipo de investimento, que garante até $1700 \% / a$ (mil e setecentos por cento ao ano) de rendimento é bem maior que nossos tradicionais índices, como a poupança. A moeda iniciou o ano cotada em $\mathrm{R} \$ 3.300,00$ (três mil e trezentos reais) e atingiu sua maior cotação antes do natal, chegando a U\$ 19.300,00 (dezenove mil e trezentos dólares), ou $\mathrm{R} \$ 63.690,00$ (sessenta e três mil, seiscentos e noventa reais). As três maiores casas de câmbio de bitcoin, as chamadas exchanges, tinham em dezembro cerca de 1,4 milhões de pessoas cadastradas, mais que o dobro de pessoas registradas na bolsa de valores de São Paulo, por exemplo (MENDONÇA, 2018).

A respeito, e conforme observado, o investimento em criptomoedas representa um negócio temerário, "por ser um arranjo em que a circulação da bitcoin não passa por supervisão e nem pelo crivo de uma instituição reguladora a garantir limites à sua criação [...]”. Em razão dessas lacunas, está evidente a insegurança das operações, e "a probabilidade de desastres financeiros existe, mas pode-se perceber reduções de assimetrias que diferenciam o comportamento nesse mercado." (BAROSSI FILHO; SZTAJN, 2015, p. 1686-1687). Portanto, falta-lhe a clareza da lealdade, da probidade e da boa-fé, e desse modo, há certa mitigação na aplicação desses princípios.

Barossi Filho e Sztajn (2015, p. 1683) apontam que:

\begin{abstract}
Se as pessoas, livremente, ajustam entre si que determinado bem tem poder liberatório, serve para liquidar obrigações, embora de circulação restrita, pode-se pensar em riscos que cada uma das partes aceita e assume. Os riscos são alocados pelo contrato. Se, porém, a circulação se expande, a falta de controle ou fiscalização pode facilitar o aumento exponencial dos riscos até que se atinja o limite da incerteza.
\end{abstract}

Não se pode admitir a não observância da ética nesses tipos de contrato. É uma questão de lógica antecedente, pois caso uma das partes já tenha de antemão objetivo atroz, todas as demais etapas estarão, consequentemente, comprometidas. Assim, a boa-fé objetiva se desdobra em três especializações funcionais, a equidade, a razoabilidade e a cooperação. No art. 924 do Código Civil de 1916, ao juiz era dada a prerrogativa de reduzir o montante da cláusula penal quando houvesse o cumprimento parcial da obrigação. Atualmente, o Código de 2002 (art. 127) impõe ao juiz o dever de reduzir equitativamente a penalidade, em outras palavras, não se trata mais de uma questão meramente discricionária. Em casos abusivos, há previsão legal no art. 413 que respalda a redução caso a multa seja manifestadamente excessiva (NEGREIROS, 2002, p. 136).

Nesse caso específico das operações econômicas envolvendo criptomoedas, deve-se buscar a ideia da finalidade econômico-social do contrato, de modo que se possa adequá-lo ao princípio da boa-fé. As operações envolvidas ainda são, de certa forma, desconhecidas, mas o que se pode afirmar é que as realizadas no território brasileiro, ou que a obrigação de fazer tenha que ser cumprida aqui, não podem se moldar de maneira diferente do que já existe no nosso ordenamento jurídico. Embora a tecnologia aplicada nas transações de bitcoins seja peerto-peer, ou seja, ponto a ponto, sem intermediários, e, diga-se, demonstre mais segurança ao usuário, nada obsta que venha permeada de outras questões que maculem o contrato a ser avençado, dando uma falsa impressão de "perfeição" da atividade.

Sob uma perspectiva constitucional, a aplicação do princípio da boa-fé objetiva é dedutível, e é com base nele que se torna plenamente possível que a norma de cogência seja imposta aos contratantes, abrangendo o direito do consumidor e indo para além dele. Com o advento do novo Código Civil “o art. 422 deverá ser interpretado em conjunto com o disposto no art. 187, 
em que o princípio da boa-fé é expressamente invocado como o limite imposto ao titular do direito, que não o pode exercê-lo de forma contrária à boa-fé.” (NEGREIROS, 2002, p. 139).

Para Tartuce (2005, p. 200):

[...] atualmente e ao contrário, tem-se defendido um "diálogo das fontes" entre o Código Civil e o Código de Defesa do Consumidor. Por meio desse diálogo, devese entender que os dois sistemas não se excluem, mas se ensinamentos. A tese foi trazida para o Brasil por Cláudia Lima Marques, utilizando os ensinamentos de Erik Jayme. Isso se dá diante de uma aproximação principiológica entre os dois sistemas legislativos, principalmente no que tange aos contratos.

A tripartição do princípio da boa-fé, portanto, é composta por uma ideologia pautada na busca de alcançá-la. Exercem função de complementariedade e muitas vezes são difíceis de se definir, caso a caso, sob que aspecto de boa-fé está sendo pautado. Desse modo, não é demais dizer que "a boa-fé está diretamente relacionada à teoria do abuso de direito nesta sua função de limitar ou mesmo impedir o exercício de direitos que emergem da relação contratual." (NEGREIROS, 2002, p. 140).

Por conseguinte, a discussão agora gira em torno do que seja uma relação contratual justa, enquanto se considere que este seja um ideal a ser alcançado. Na era clássica, "o princípio do equilíbrio econômico incide sobre o programa contratual, servindo como parâmetro para avaliação do seu conteúdo e resultado, mediante a comparação das vantagens e encargos atribuídos a cada contratante" (NEGREIROS, 2002, p. 156-157). Já na fase contemporânea, a preocupação reside no contratante vulnerável, em razão da desproporção entre o poder negocial dos contratantes, e assim, "a disciplina contratual procura criar mecanismos de proteção da parte mais fraca, como é o caso do balanceamento das proporções." (NEGREIROS, 2002, p. 157). O preceito da justiça contratual, portanto, desprendeu-se da verificação da autonomia privada para averiguação dos efeitos que essa liberdade produziu. Daí porque se entenda que, nos dias atuais, embora o contrato possa ser avençado sob a égide da autonomia privada, não significa que não possa ser posteriormente modificado, por apresentar cláusulas que transpareçam ausência de equilíbrio contratual entre as partes.

Para Teresa Negreiros (2002, p. 155):

A vedação a que as prestações contratuais expressem um equilíbrio real e injustifi-
cável entre as vantagens obtidas por um e por outro dos contratantes, ou, em outras
palavras, a vedação a que se desconsidere o sinalagma contratual com seu perfil
funcional, constitui expressão do princípio consagrado no art. $3^{\circ}$, III, da Constitui-
ção: o princípio da igualdade substancial, pressuposto - como é notório - da justiça
social, o contrato não deve servir de instrumento para que, sob a capa de um equilí-
brio meramente formal, as prestações a favor de um contratante lhe acarretem um
lucro exagerado em detrimento do outro contratante.

A depender da relação que se engendra, do negócio que é pactuado, e em razão do já dito risco premente que rodeia a aquisição e venda de criptomoedas, o desequilíbrio contratual pode causar efeitos deletérios, pois geralmente não se sabe com quem se está negociando, pontualmente em decorrência de ser o ambiente virtual marcado pela impessoalidade. Num panorama não muito animador para aqueles que desejam investir nessa nova tecnologia, CVMComissão de Valores Mobiliários no Brasil divulgou uma nota em outubro e 2017, reconhecendo, a depender do contexto econômico, que a emissão de ativos virtuais podem representar valores mobiliários, porém, não mencionou qualquer interesse em regulamentá-la.

Apesar das incertezas que envolvem essas negociações, as empresas devidamente constituídas, cujo objetivo seja a prestação de serviços envolvendo operações comerciais com criptomoedas, devem obedecer ao princípio da boa-fé objetiva. Traçando um paralelo entre essas 
atividades e as que já são efetuadas em ambiente virtual, por terem diversas semelhanças em relação aos direitos do consumidor, e por não fugiram à responsabilidade social:

\begin{abstract}
[...] as empresas virtuais também são responsáveis pela edificação do futuro da humanidade. Mesmo com a estrutura virtual, a empresa tem que cumprir a função social/solidária nos negócios virtuais, agindo com a verdade, respeito, boa-fé, ética, segurança e não visar lucro a qualquer preço. Deve visar o bem estar coletivo para garantir uma sociedade digna e justa para as presentes e futuras gerações. (CARDOSO; CARMO, 2017, p. 16).
\end{abstract}

Em relação à eficácia perante terceiros, é salutar analisá-la à luz das regras que devem ser observadas nos contratos de aquisição e venda de moedas virtuais em razão do blockchain, bancos de dados públicos que registram as atividades envolvendo as criptomoedas. Bem, se os bancos de dados são públicos, implica dizer que qualquer pessoa pode ter acesso, e, dessa forma, "garante" que terceiros possam tomar conhecimento das transações que tenham interesse.

No site www.blockchain.info/pt, cuja plataforma está em Luxemburgo (embora o blockchain esteja distribuído em diversos computadores, descentralizadamente), é possível acompanhar as movimentações das transações feitas pelas empresas "mineradoras" e suas atividades comerciais, como uma espécie de bolsa de valores virtual. Parte do texto está em português, sendo perfeitamente possível, para quem possui conhecimento na área, fazer esse acompanhamento, destacando somente que quem não possui conhecimento algum não vai conseguir decodificar os dados nele existentes.

Partindo-se da autonomia privada como vetora dessa atividade, a condição de parte, na concepção clássica, "é definida pela manifestação da vontade no momento da conclusão do contrato; [...] é a vontade de estar ligado ao contrato [...]". Assim, "o alargamento da noção de parte faz-se, pois, no tempo, sendo por isso um conceito evolutivo. Por outro lado, também a lei pode impor a certas pessoas cuja vontade não participa da formação do vínculo a formação de parte." (NEGREIROS, 2002, p. 222). O novo Código Civil indica, nesta ótica, que a liberdade de contratar seja praticada, de acordo com a razão e nos limites da função social do contrato, e a própria lei respalda a força obrigatória do contrato, que encontra sua razão de ser nos fins almejados pelo direito em geral, sob os fundamentos da justiça social, segurança, bem comum, dignidade da pessoa humana. (NEGREIROS, 2002, p. 228).

Por esses fundamentos, vê-se a caracterização do terceiro como condição de parte, e dessa forma, na relação negocial envolvendo as criptomoedas, ele pode utilizar instrumentos jurídicos para fazer valer os seus direitos ou evitando que haja o descumprimento das obrigações contratuais, do mesmo modo que o credor poderá se insurgir caso haja comportamento temerário de terceiro, numa relação cíclica que necessita ser harmoniosa sob pena de causar sérios prejuízos na relação contratual.

\title{
CONCLUSÃO
}

Viu-se ao longo da pesquisa que as relações contratuais envolvendo moedas virtuais ainda se encontram em território não explorado totalmente e as questões relativas a segurança das transações e das informações permanecem duvidosas. Por ser uma novíssima tecnologia, cujas transações se dão apenas em meio virtual, dentro de plataformas especializadas com atuação no mundo inteiro, a fiscalização e regulamentação em nosso país está longe de ser exercida. Não que não haja preocupação da Comissão de Valores Imobiliários e o mercado financeiro como um todo, mas as peculiaridades dessas transações ainda despertam certa desconfiança. 
A autonomia privada como pilar da relação contratual clássica cunhada por Enzo Roppo não deixa de exerce papel de relevo nas negociações envolvendo aquisição e venda de moedas virtuais. Conforme restou evidenciado, é através dela que a negociação se exterioriza quando permeia a vontade antecedente das partes até a realização do negócio jurídico, traçando um perfil de subjetividade como forma determinante para escolha desse tipo de avença.

Apesar da manifestação inconteste das partes, e estando em termos a avença pretendida, referida negociação não escapa à tutela dos demais princípios que norteiam a teoria geral dos contratos, nem tampouco os princípios gerais do direito. Fundamentos de validade e compreensão social como a impossibilidade de imposição de cláusulas abusivas, de onerosidade excessiva, de fraude ou a escolha de objeto ilícito são algumas das proibições que também alcançam a matéria dos contratos virtuais de criptomoedas.

A dificuldade de constatação desses gravames talvez seja o maior desafio enfrentado atualmente, uma vez que o ambiente virtual é capaz de macular e esconder detalhes que apenas aqueles que estão inseridos no contexto ou possuem conhecimento para decifrar os dados contidos no blockchain serão capazes de detectar, e talvez não, dependendo da situação. A facilidade de acesso a esse tipo de investimento, pautado por rendimentos e valores fora da realidade da maioria das operações comerciais e investimentos conhecidos, tem sido motivos determinantes para que cada vez mais pessoas a procurem, apesar de saberem dos riscos decorrentes e da volubilidade da moeda virtual.

O fato é que esses novos princípios do contrato, pautados na boa-fé, equilíbrio contratual e a função social são primordiais para que se tenha uma relação balanceada e transparente. Contudo, não é tarefa fácil de ser feita nem mesmo nos contratos tradicionais, nos quais, de certa forma, há possibilidade de formalizá-lo fisicamente. Conceber o contrato como uma ferramenta a serviço da pessoa, da sua dignidade e de seu desenvolvimento, diante dos princípios constitucionais, significa que nele serão necessários constar valores como justiça social e proteção do consumidor, trazendo uma ruptura com a autonomia privada.

Portanto, é salutar reafirmar a necessidade de aplicação de todos os princípios que regem a teoria geral dos contratos, tendo em vista, principalmente, que as atividades negociais envolvendo a aquisição e venda de criptomoedas estão em expansão de proporções geométricas, sendo inseridas nas mais diversas áreas econômicas. A mitigação desses princípios, como ora se observou, leva a uma gama de incertezas que de certa maneira impedem ou retardam seu crescimento econômico, já que não se pode afirmar de antemão que seja uma atividade ilegal.

Inegável a evolução trazida pelo novo Código Civil no tocante aos contratos, modernizando as relações negociais para que estas estejam mais intimamente ligadas ao fim a que se destinam, com a possibilidade de modificação das cláusulas e termos contratuais, na medida em que estejam em desacordos com os novos ditames. Assim, procura-se compatibilizar essa nova realidade com as inovações tecnológicas que se apresentam, de modo que nada possa estar num patamar supralegal. No Brasil a doutrina avança um pouco mais que a jurisprudência, no sentido de tentar dialogar a respeito dessas novas perspectivas, que de início se impõem a uma modernização de modelo contratual quase forçada. É dizer que o direito terá que se adequar a essa nova realidade e vice-versa, num todo harmonioso que possibilite o crescimento econômico sem que reverbere à ilegalidade.

A crescente procura dos brasileiros por criptomoedas, na verdade, demonstra não apenas o interesse específico nessa nova tecnologia, mas uma alternativa de investimento que até então tem proporcionado ganhos extraordinários que nenhum fundo de investimento sequer sonha em realizar. Por ser um comércio acessível, em face de sua abertura digital pública e às casas de câmbio, qualquer pessoa do povo pode ter acesso e adquirir as criptomoedas, mesmo 
cientes dos riscos a ela vinculados. A cobrança de taxas de administração e a possibilidade de repasse de parte desses lucros de rendimento não tem afastado a população, cada vez mais em busca de uma saída para a crise de investimentos que há anos se tem observado no Brasil. Por esta e outras razões, principalmente por não ter como ignorar essa atividade e a necessidade de tutelar direitos e obrigações, até em face do recolhimento de impostos, essa atividade reclama regulamentação o mais rápido possível.

Com o objetivo de proporcionar maior credibilidade e segurança às partes contratantes, terceiros interessados e o sistema como um todo, necessário se faz a continuidade dos estudos e a observância do desenrolar em relação à Comissão de Valores Mobiliários, haja vista se tratar de situação que mais cedo ou mais tarde terá que ser pesquisada, avaliada e por fim, regulamentada.

\section{REFERÊNCIAS}

BAROSSI FILHO, Milton, SZTAJN, Rachel. Natureza jurídica da moeda e desafios da moeda virtual. Revista Justitia, São Paulo, n. 1, p, 251-268, jan/dez. 2013;2014;2015.

BOULOS, Daniel Martins. A autonomia privada, a função social do contrato e o novo Código Civil. In: ALVIM, Arruda; CÉSAR, Joaquim Portes de Cerqueira; ROSAS, Roberto (Coord.). Aspectos Controvertidos do novo Código Civil. São Paulo: Revista dos Tribunais, 2003. p. 125-136.

CARDOSO, Gleissa Mendonça Faria; CARMO, Valter Moura do. Função Social/Solidária da Empresa nos Negócios Virtuais. Revista Jurídica da FA7, Fortaleza, v. 14, n. 2, p. 137-157. jul./dez. 2017. Disponível em: <http://www.uni7.edu.br/periodicos/index.php/revistajuridica/ article/view/509/371>. Acesso em 25 abr. 2018.

FERNANDES, Jean Carlos; SOUZA, Wallace Fabrício Paiva. A aplicação da teoria do finalismo mitigado nos contratos empresariais pelo superior tribunal de justiça e o desestímulo ao empreendedorismo. Revista Argumentum - RA, Marília/SP, v. 18, n. 1, p. 43-68, jan./abr. 2017.

GLITZ, Frederico Eduardo Zenedin. A contemporaneidade contratual e a regulamentação do contrato eletrônico. In: SILVEIRA RAMOS, Carmem Lucia; TEPEDINO, Gustavo; BARBOZA, Heloísa Helena; GEDIEL, José Antonio; FACHIN, Luiz Edson; BODIN DE MORAES, Maria Celina. (Org.). Diálogos sobre Direito Civil: construindo uma racionalidade contemporânea. Rio de Janeiro: Renovar, 2002, p. 209-246.

GUSSON, Cassio. FBI fecha corretora de criptomoedas Coingather. Criptomoedas fácil.com, 20 mar. 2018. Disponível em: <https://www.criptomoedasfacil.com/fbi-fecha-corretora-decriptomoedas/>. Acesso em: 25 abr. 2018.

GONÇALVES, Carlos Roberto. Direito Civil Brasileiro. v. 3: contratos e atos unilaterais. 10 ed. São Paulo: Saraiva, 2013.

MARTINS, Armando Nogueira da Gama Lamela. Quem tem medo do Bitcoin? O funcionamento das moedas criptografadas e algumas perspectivas de inovações institucionais. Revista Jurídica Luso Brasileira, Lisboa, ano 2, n. 3, p. 137-171, maio/jun. 2016. Disponível em: <https://www.cidp.pt/publicacoes/revistas/rjlb/2016/3/2016_03_0137_0171.pdf>. Acesso em 25 abr. 2018. 
MENDONÇA, Heloisa. Brasil vive febre de investimentos em bitcoins, de empregadas domésticas a bancários. El País, São Paulo, 6 fev. 2018. Economia. Disponível em: <http:// brasil.elpais.com/brasil/2018/01/30/economia/1517320821_596729.html>. Acesso em: 25 abr. 2018.

NALIN, Paulo. Do contrato: Conceito Pós-Moderno. Em busca de sua Formulação na Perspectiva Civil-Constitucional. Curitiba: Juruá, 2003.

NASSIF, Luis. Crise e criatividade permitiram o avanço das criptomoedas no Brasil. GGN, 14 mar. 2018. Economia. Disponível em: <http://jornalggn.com.br/noticia/crise-e-criatividadepermitiram-o-avanco-das-criptomoedas-no-brasil>. Acesso em: 25 abr. 2018.

NEGREIROS, Teresa. Teoria do Contrato. Novos Paradigmas. Rio de Janeiro: Renovar, 2002. p. 116-117.

PEREIRA, Caio Mário da Silva. Instituições do Direito Civil. Contratos. 20. ed. v. III. Rio de Janeiro: Forense, 2016. p. 25-26.

RODRIGUES JUNIOR, Otávio Luiz. Autonomia da vontade, autonomia privada e autodeterminação. Notas sobre a evolução de um conceito na Modernidade e na Pós-modernidade. Revista de Informação Legislativa, Brasília, ano 41, n. 163, p. 113-130, jul./set. 2004.

ROPPO, Enzo. O Contrato. Coimbra: Almedina, 1998.

SZTAJN, Rachel. Sistema Financeiro: entre estabilidade e risco. Rio de Janeiro. Elsevier, 2011.

TARTUCE, Flávio. A função social dos contratos, a boa-fé objetiva e as recentes súmulas do Superior Tribunal de Justiça. In: CANEZIN, Claudete Carvalho (Coord.). Arte Jurídica: biblioteca científica de Direito Civil e Processo Civil, v. 3. Curitiba: Juruá, 2005. p. 195-206.

TEPEDINO, Gustavo. Notas sobre a função social dos contratos. In: TEPEDINO, G e FACHIN, LE (Coord.). O Direito e o Tempo: Embates Jurídicos e Utopias Contemporâneas Estudo em Homenagem ao Professor Ricardo Pereira Lira. Rio de Janeiro: Renovar, 2008. p. 389-399.

Recebido em: 30 mar. 2018. Aceito em: 10 maio 2018. 